\title{
ON PSYCHIATRY AND PSYCHOSOMATICS
}

\author{
E. Neu 1, M.C. Michailov 1, H. Schumitz 1, S. Molnár 1, U. Welscher 1, \\ H.W. Bauer 2, A. Hofstetter 3, E.R. Weissenbacher 4, M. Schratz 5, G. Weber 6
}

1 Inst. Umweltmedizin (IUM) c/o ICSD/IAS e.V., POB 340316, 80100 Muenchen, Germany (Int.Council Sci.Develop./Int.Acad.Sci. Berlin-Bratislava-Innsbruck-Muenchen-

New Delhi-Paris-Sofia-Vienna).

2 Univ. Muenchen and Free Univ. Berlin, Med. Fak., Munich, Germany.

3 Univ. Muenchen, Klinikum Grosshadern (Dir. a.D.), Munich, Germany.

4 Univ. Muenchen Med. Fak. \&, Premium Med. Clinic (Dir.), Munich, Germany.

5 Univ. Innsbruck, School of Education (Dean), Innsbruck, Austria.

6 Univ. Lxbg. \& Vienna, Fac. Psychol. (Dean), Vienna, Austria.

INTRODUCTION: New models for psychiatry incl. psychosomatic (Th.v.UEXKÜLL) and somato-psychic theories (Y.IKEMI), appointed during opening-ceremony of ICPM-Congr. in Kobe by Emperor AKIHITO: "total symptoms of mind-body, seeking ways of holistic care" are to be discussed.

Psychopathology in context of therapy\&prophylaxis includes high complex interaction of psychic-physiological-pharmacologicalsocial factors.

METHODS: Psychosomatic practices of occidental/oriental medicine (patients/probands). Evaluation of psychic-"polarattitude-list"/physiological-parameters: heart-rate, bloodpressure,etc. (ref.).

RESULTS: Observations about influence of music[1], respiratory[2], yoga-physical[3] therapies on psychosomatic parameters demonstrate strong positive effects. Items of categories psycho-physiological (relaxed), emotional (tranquil/happy), cognitive (few/ordered-thoughts), voluntary (active/spontaneous), social (open/assertive), consciousness (clear/sleepy) are significantly positive changed $25-50 \%$. The 3 therapies have specific psychic effects, e.g. items "relaxed/ tranquil" after respiratory- (+45/50\%)/music-therapy (+20/5\%), also "open" $(+25 \%)$ are positive, but negative after respiratorytherapy $(-20 \%)$. Items are stronger changed before then after gynecological-urological-surgical-intervention. Higher effects are observed for investigators\&children than of students of psychology. Psychic effects are correlated with positive physiological ones, e.g. heart/respiratory-frequency decreased $25-30 \%$, voluntary-apnoea prolonged $55 \%(p<0.05-0.01, n=145)$.
CONCLUSIONS: Integrative psychosomatic therapy incl. occidental-oriental (yoga, tai-chi, Zen, etc.) approaches could be applied for psychic disorders. Different methods are with preference, e.g. for depression is suitable respiratory/physicaltraining (activation) incl. for gynecological-urological patients, for mania: music-therapy (inhibitory effect), for epilepsy: respiratorytherapy - hypo-/hypercapnia: inhibitory/excitatory effects on CNS-structures. Systematic research about influence of psychosomatic therapies counteracting disturbances of psychiatric patients could support UNO-Agenda21 for better health, education, etc. on global level.

References: EPA-2018-Nice, Eur. Psychiatry 48/S1, S623\&567\&662. WPA-2018-Mexico-City (in-press); 2011Buenos-Aires, AB:PO1.200. ICPM-2017-Beijing, AB:ID: 648493,648895,648749,648878; -2005-Kobe, J.Psychosom.Res. 58:85-86. IUPsyS-2012-Cape-Town, IntJPsychol 47:407; -2008-Berlin, 43/3-4:154,248,615,799; -2004 Beijing, AB:49,587. IUPS-2017-Rio-de-Janeiro, AB:No. 997,999,1001,1003: -2009-Kyoto. J.Physiol.Sci., 59/S1:168\&214\&447-8.
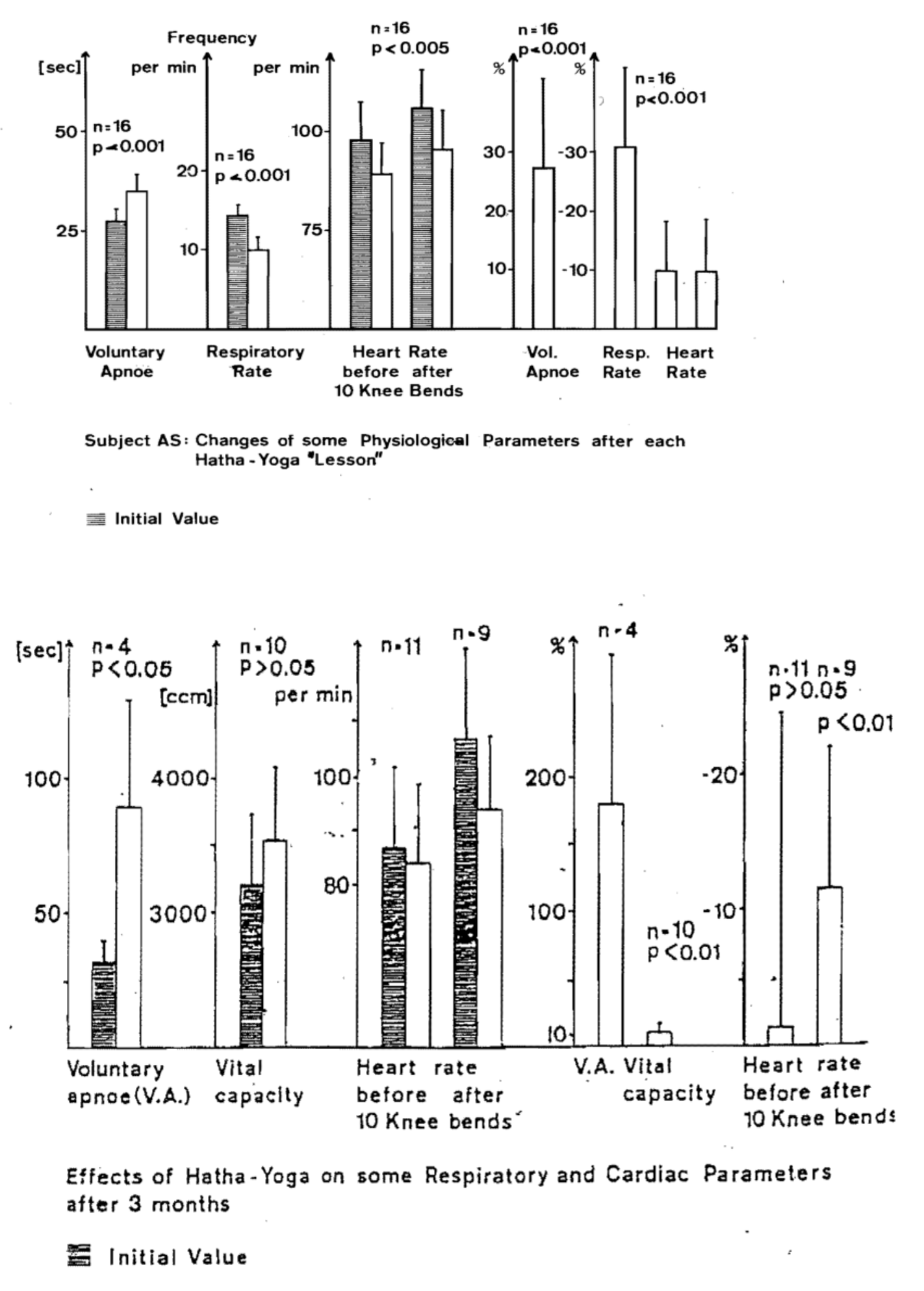